\title{
Effect of Duplex Aging Heat Treatment on the Stress Corrosion Cracking Behavior of Ti-6Al-4V $\alpha+\beta$ Titanium Alloy in Methanol
}

\author{
Paulo César Paroli Santos Junior ${ }^{a^{*}}$ (D), Edmilson Otoni Correa ${ }^{a}$ (D) \\ ${ }^{a}$ Universidade Federal de Itajubá (UNIFEI), Instituto de Engenharia Mecânica, Itajubá, MG, Brasil
}

Received: September 30, 2020; Revised: January 24, 2021; Accepted: February 16, 2021

\begin{abstract}
The influence of duplex aging (DA) heat treatment and consequent microstructural changes in the stress corrosion cracking (SCC) resistance of Ti-6Al-4V $\alpha+\beta$ titanium alloy was examined through constant load SCC test and metallographic examination. The time for fracture (TFF) of duplex aged samples in the SCC test was compared with single aged samples TFF. The results of the constant load SCC test showed an improvement in corrosion resistance with the second stage of aging in the duplex aging heat treatment. Microstructural examination revealed a preferential path for SCC crack propagation through prior $\beta$ grains (lamellar structure alternating $\alpha$ and $\beta$ phases) which indicated that the bigger SCC resistance observed in DA samples is a consequence of greater $\beta$ phase decomposition due to the second stage of aging. It wasn't observed a bigger grain growth in the DA heat treatment, in comparison with single aged (SA) samples. The observed fracture aspect was mixed (ductile-fragile) in peripheral regions and ductile in the interior of the body proofs, what indicate the major influence of SCC in the fracture mechanism.
\end{abstract}

Keywords: Ti-6Al-4V, Stress Corrosion Cracking, Duplex aging.

\section{Introduction}

Because of its high strength/weight ratio, its good mechanical properties in high temperatures and its high corrosion resistance, about $50 \%$ of the titanium produced in the world becomes Ti-6Al-4 $\mathrm{V}^{1}$. It has several applications, such as biomedical implants and aerospace components.

Commonly, this alloy is putted into service after some solution and aging heat treatment ${ }^{2}$, once these treatments gives substantial raise in strength to Ti-6Al-4V alloy ${ }^{3}$.

The SCC resistance is a very important variable in alloys used in aerospace components. That's because these components, in service, suffer simultaneous influence of thermal and mechanical tensile, together with potentially corrosive environments ${ }^{4}$. Solution and aging heat treatments can affect the susceptibility of $\alpha+\beta$ titanium alloys to $\mathrm{SCC}^{5}$.

Commercially pure titanium is constituted, at room temperature, of a single phase, with hexagonal close packed (HCP) crystal structure, this is called $\alpha$ phase. Titanium exhibit an allotropy transformation when reaching $882^{\circ} \mathrm{C}$ (critical temperature). In temperatures above the critical temperature, commercially pure titanium is constituted of a single phase, with body centered cubic (BCC) structure, it is called $\beta$ phase $^{6}$. The addition of alloying elements can stabilize $\alpha$ or $\beta$ phases, because of this, titanium alloys can present, at room temperature, a single $\alpha$ structure, a single $\beta$ structure or a mix of this two phases $(\alpha+\beta$ alloys). Aluminum is an $\alpha$ stabilizer, vanadium is a $\beta$ stabilizer, that's why Ti$6 \mathrm{Al}-4 \mathrm{~V}$ is classified as an $\alpha+\beta$ alloy $^{2}$.

The solution heat treatment in $\alpha+\beta$ titanium alloys, like Ti-6Al-4V, is used for gaining strength with the retention

*e-mail:jrparoli@hotmail.com of bigger amount of $\beta$ phase at room temperature. The material is heated until its temperature is close to the critical, so it is quenched in water and the $\beta$ phase is retained in a martensitic structure, made of alternate lamellae of $\alpha$ and $\beta$. The martensitic grains are called prior $\beta$ grains. The aging heat treatment is realized after the solution treatment, its objective is to decompose some of the martensitic structure, resulting in the nucleation and growth of new $\alpha$ grains. After solution and aging, Ti-6Al-4V shows a mixed structure, formed by the combination of prior $\beta$ grains and $\alpha$ grains ${ }^{1}$.

The DA heat treatment has the same objectives of the SA heat treatment described above. The difference between them is that in DA it is done a second stage of aging after the standard procedures ${ }^{7}$. This heat treatment was developed for a strength gain, mainly in $\beta$ titanium alloys, the result of two stages aging is a more uniform and controlled decomposition of martensitic structure, joining strength gain and ductility maintenance ${ }^{8}$.

The main objective of this work is to analyze the effects of an additional stage of aging in SCC resistance in methanol, in order to put it in perspective a new route of heat treatment for titanium $\alpha+\beta$ alloys submitted to critical circumstances of tension and corrosion.

\section{Experimental Procedure}

\subsection{Heat treatment}

For the solution heat treatment, samples were heated until they are next to the critical temperature for Ti-6Al-4V. The treatment was done at $900^{\circ} \mathrm{C}$, in order to reach a high level of hardness ${ }^{9}$. According to literature ${ }^{2}$ when reaching $990^{\circ} \mathrm{C}$ 
this alloy is fully composed of $\beta$ phase. The samples were kept in $900^{\circ} \mathrm{C}$ for 8 minutes, in order to make the temperature uniform along the material, after that, they were quenched in water with moderate agitation.

The aging treatments were done in controlled argon atmosphere oven, in order to prevent the formation of oxides. The first aging stage was done at $600^{\circ} \mathrm{C}$ for 1 hour with oven cooling, this higher aging temperature was chosen in order to cause a strong decomposition of solution resulting lamellar grains ${ }^{10}$. The second aging stage was done at in a lower temperature of $450^{\circ} \mathrm{C}$, for 1 hour, also with oven cooling. The choice of such lower temperature has the objective of testing the occurrence of lamellar grains decomposition in a lower temperature aging. For comparison reasons some samples weren't submitted to the second aging stage.

\subsection{SCC testing}

It was used the constant load method for the SCC test, in accordance with ASTM G49 ${ }^{11}$. The tests were done with 3 millimeter thick rectangular specimens, Figure 1 shows details of the specimens geometry. The corrosive medium used in the test was methanol with less than $0,1 \%$ of water. Every test was realized at room temperature. After machining, the specimens were grinded with abrasive paper of 200 and 400 mesh. The specimens were notched with broaching machine. The specimens preparation was done following the instructions in ASTM G58 ${ }^{12}$ and ASTM E8 ${ }^{13}$.

Specimens were submerged in methanol in a PTFE coated recipe, the mechanical tension was applied using stainless steel arms attached to free weights. TFF was the parameter used for determining the SCC susceptibility, it was measured in an automated way, using a chronometer attached to a power cell. The SCC test was realized for 3 specimens in each heat treatment condition.

The load was fixed in $830 \mathrm{MPa}$, about $85 \%$ of the yield strength of Ti-6Al-4V $\mathrm{V}^{14}$. This tension is enough for causing SCC in such alloy in methanol environment ${ }^{15}$.

\subsection{Microstructural characterization}

Specimens of both heat treatment conditions were sectioned in small pieces before and after SCC testing for microstructural characterization. The resulting samples were grinded with 200, 400, 600 and 1000 mesh abrasive paper and polished with OPU. Kroll's reagent (aqueous solution with 3\% fluoridric acid and $6 \%$ nitric acid) was used for revealing microstructures. Optical and scanning electrical microscopy were used for characterization, an image treating software was used to determine volumetric fraction of different phases in each sample.

\section{Results and Discussion}

\subsection{Microstructural changes with heat treatment}

On its annealed form, a Ti-6Al-4V SEM micrograph is presented in Figure 2. The microstructure is mostly composed of $\alpha$ phase (dark regions), with some retained $\beta$ phase in grain boundaries (light regions). It is noted a globular shape for $\alpha$ grains, the volumetric fraction of $\beta$ phase for this sample is about $40 \%$ (average).
Figure 3 exhibits a SEM micrograph of SA Ti-6Al-4V sample. The heat treatments applied in this sample caused strong alterations in the material structure, after SA heat treatment the sample presents a portion of $\alpha$ grains (dark regions) and a portion of prior $\beta$ lamellar grains (dark/light lamellae). The lamellar grains are a result of martensitic transformation during solution treatment. The volumetric fraction of prior $\beta$ grains is $63 \%$.

Figure 4 is a SEM micrograph of DA Ti-6Al-4V sample. It is seen a very similar structure, in comparison with SA sample. It is clearly seen the lamellar structure in prior $\beta$ grains, and the presence of $\alpha$ grains (dark regions). The volumetric fraction of prior $\beta$ grains is $45 \%$.

It is noted a substantial decrease in volumetric fraction of prior $\beta$ grains after the second stage of aging ( $28 \%$ drop), what proves that duplex aging results in a more efficient

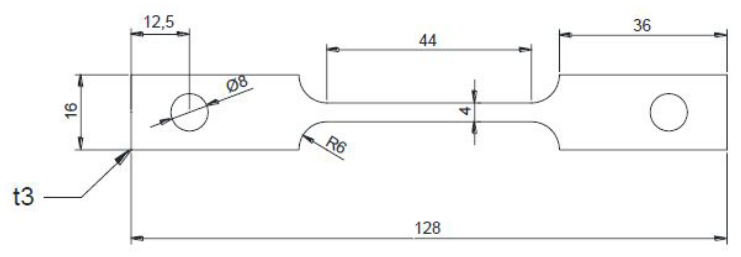

Figure 1. Specimen Dimensions.

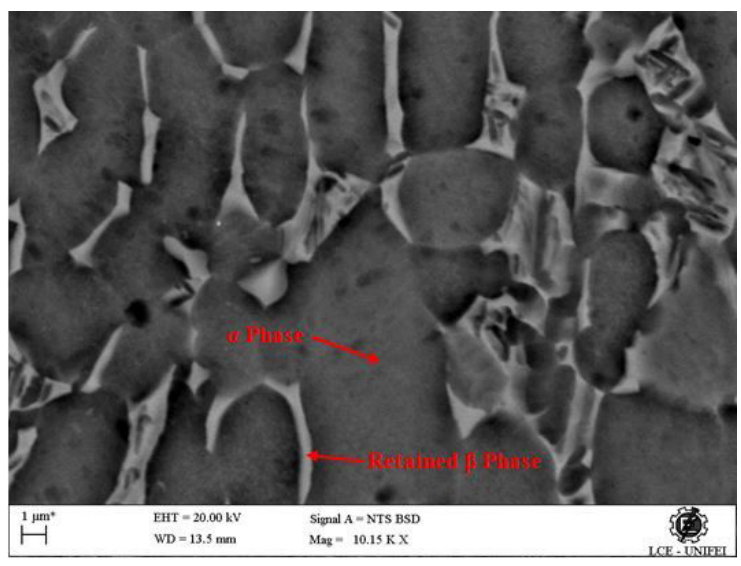

Figure 2. Annealed Ti-6Al-4V Microstructure.

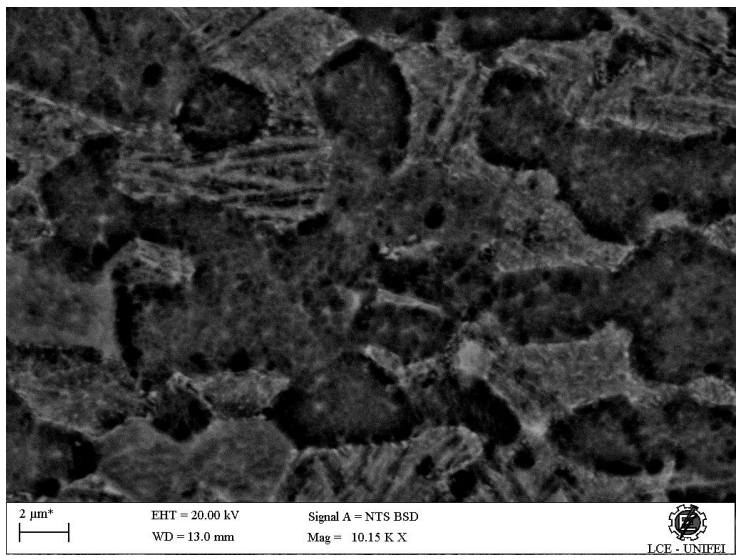

Figure 3. SA Ti-6Al-4V Microstructure. 
martensitic decomposition. Grain size analysis doesn't indicate grain growth during the second aging stage (remains ASTM 10 for both samples), making impossible any chance of strength loss in DA due to grain growth. This grain size maintenance is explained by the relatively low temperatures used in the second aging stage.

\subsection{SCC tests results}

As mentioned in the Experimental Procedure, the parameter adopted to evaluate the SCC resistance in determined sample was TFF. It was measured the total time, in minutes, since the load application and the complete fracture of specimen.

The results of this procedure, presented in Table 1, showed that DA samples were substantially more resistant to SCC in methanol, with a $830 \mathrm{MPa}$ load, in comparison to SA samples. The average TFF of DA specimens was 7\% longer than the average for DA samples.

This SCC resistance improvement indicates a positive correlation between prior $\beta$ grains decomposition and SCC resistance, for Ti-6Al-4V in methanol.

\subsection{Microstructure analysis after SCC tests}

In order to understand the mechanism of SCC cracking propagation in Ti-6Al-4V alloy, SEM micrographs were carried out in fractured regions, with the objective of understanding

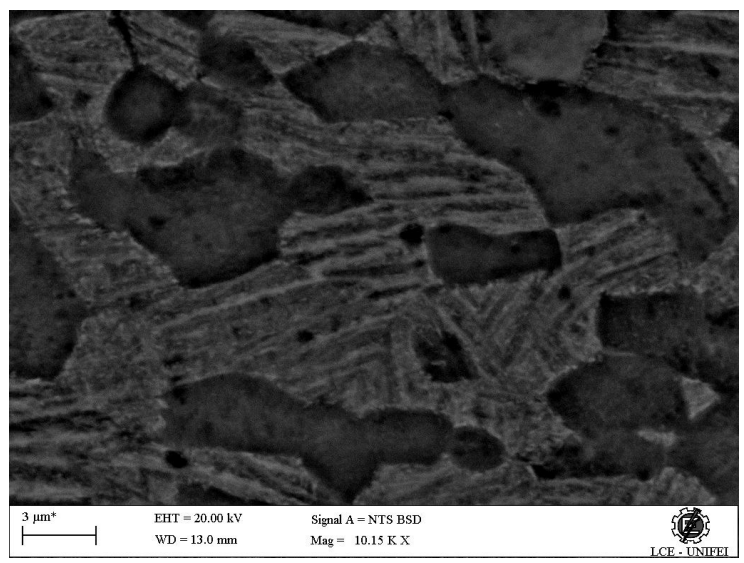

Figure 4. DA Ti-6Al-4V Microstructure.

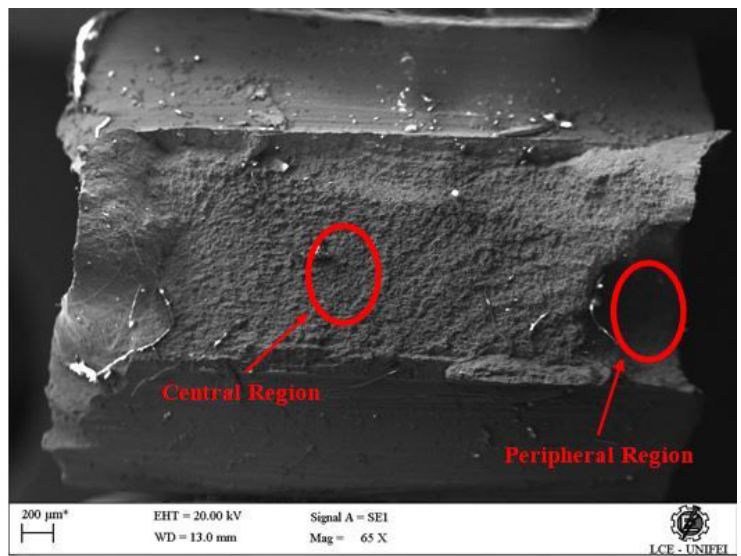

Figure 5. Global Vision of Fractured Specimen. what microstructural changes were responsible for the SCC resistance raise.

After SCC tests, the fractured region in specimens were cut in small samples, in order to realize the micrographs. Figure 5 presents a global vision of the fractured surface in a SA sample, the surface was divided in different regions, as indicated in Figure 5.

Figure 6 is a detailed vision of the central region in SA sample. It is clearly seen a predominance of dimples, characterizing a ductile aspect fracture. In Figure 7, it is seen a mixed aspect fracture, joining particular structures of ductile materials (dimples) and others of brittle materials (cleavage plans).

In Figures 8 and 9 it is showed the central and peripheral regions for a DA sample. The fracture structures are the same seen for SA samples, with predominance of dimples in central area and a mix of dimples and cleavage plans in borders.

Figures 10 and 11 are examples of cracks founded next to fractured regions of specimens. It is observed a

Table 1. Average TFF.

\begin{tabular}{cc}
\hline Heat Treatment & Average TFF (Min) \\
\hline Single Aging & 591,4 \\
\hline Duplex Aging & 634,4 \\
\hline
\end{tabular}

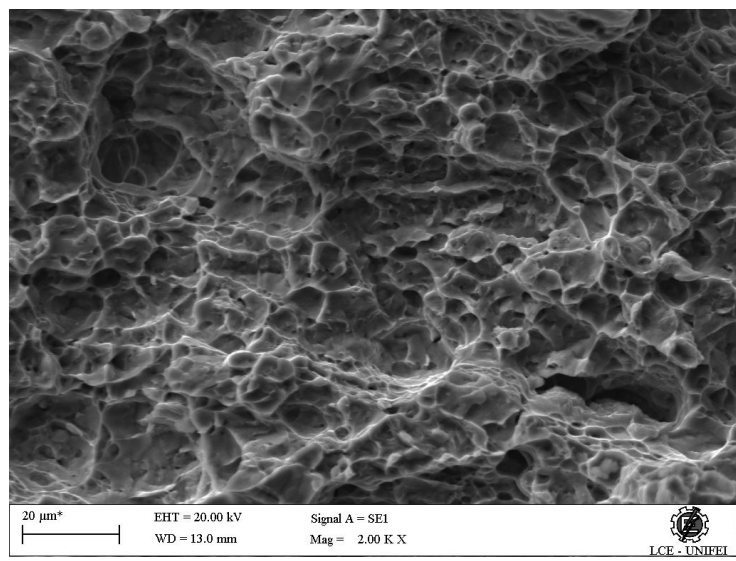

Figure 6. SA Sample: Dimples in Central Region.

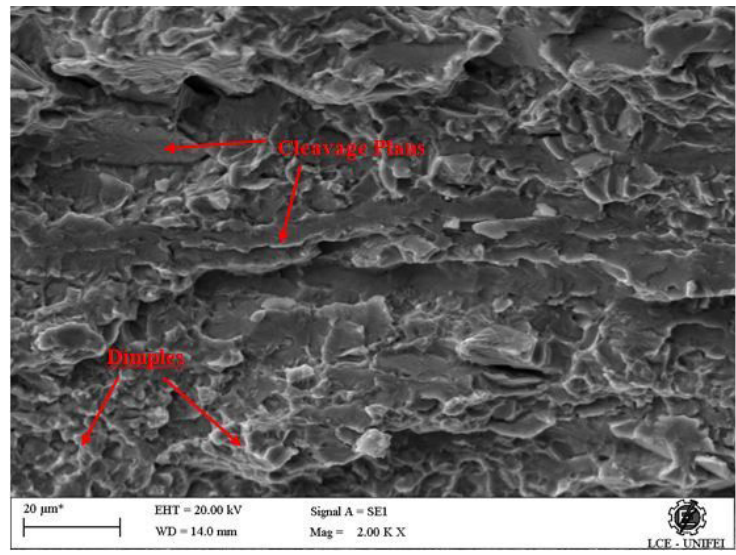

Figure 7. SA Sample: Mixed Fracture Aspect in Peripheral Region. 


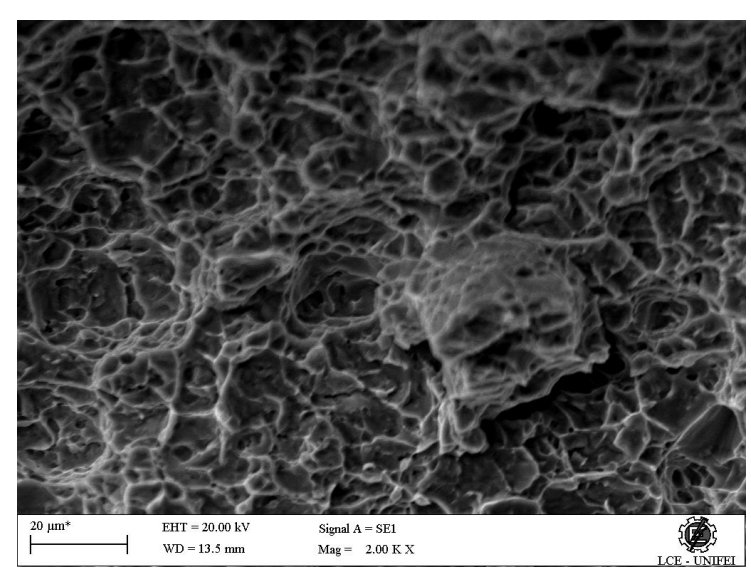

Figure 8. DA Sample: Dimples in Central Region.

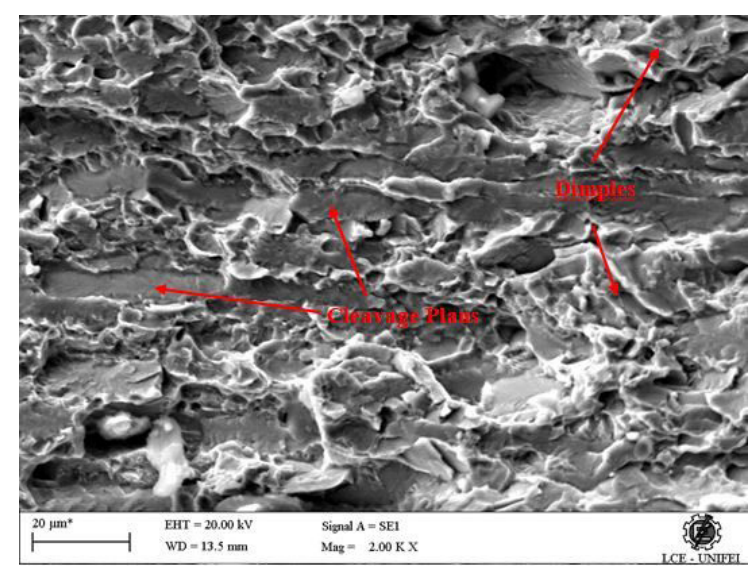

Figure 9. DA Sample: Mixed Fracture Aspect in Peripheral Region.

transgranular mechanism of propagation, with preferential path in $\beta$ grains (light regions).

The preferential propagation of cracks in prior $\beta$ grains explains the lower susceptibility to stress corrosion cracking of TI-6Al-4V after DA aging, in comparison with SA samples, once the second aging stage caused stronger $\beta$ phase decomposition, reducing the volumetric fraction of prior $\beta$ grains.

\section{Conclusions}

From this study, it can be drawn the following conclusions:

The two stages aging process causes a stronger decomposition of lamellar structure in prior $\beta$ grains (decrease from $63 \%$ to $45 \%$ in volumetric fraction, comparing with single aged specimens), without any substantial grain growth.

The concomitant presence of pure ductile fracture in the central region and ductile-brittle fracture in peripheral regions proves the occurrence of SCC in Ti-6Al-4V specimens tensioned in methanol environment and its important role in its fracture. All specimens went to failure with loads below their yield strength.

The most effective prior $\beta$ lamellar grains decomposition in the second aging stage raised the SCC resistance of the alloy in general.

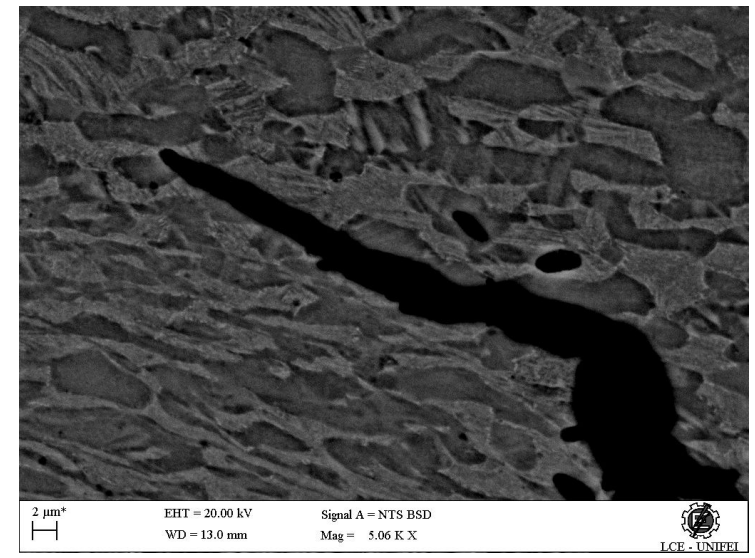

Figure 10. SCC Crack in DA Sample.

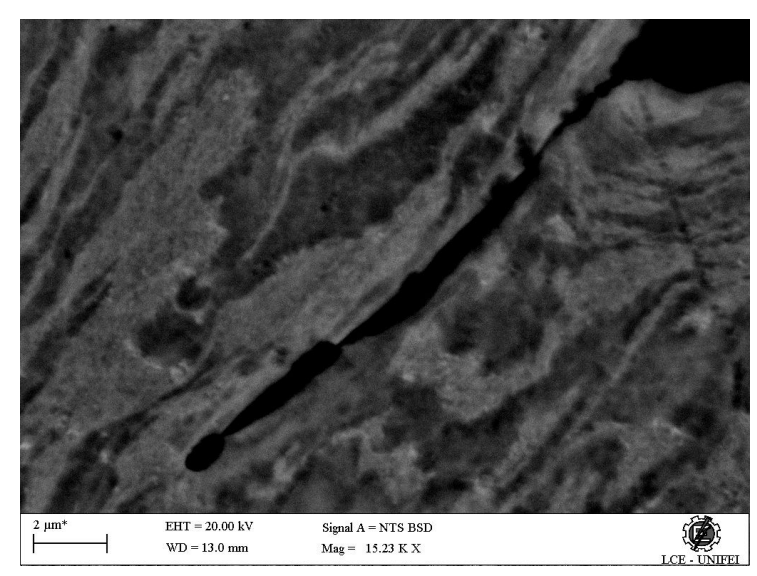

Figure 11. SCC Crack in SA Sample.

Micrograph analysis showed a transgranular propagation of stress corrosion cracks. Prior $\beta$ grains were the preferential path for crack initiation and propagation.

\section{References}

1. Tanaka S, Morita T, Shinoda K. Effects of short-time duplex heat treatment on microstructure and fatigue strength of Ti6Al-4V alloy. In: 13th International Conference on Fracture; 2013; Beijing, China. Proceedings. USA: Curran Associates, Inc.; 2013.

2. Pederson R. Microstucture and phase transformation of Ti-6Al4V [thesis]. Lulea: Lulea University of Technology; 2002.

3. Masete S, Mutombo K, Siyasite C, Stumpf W. Effect of ageing treatment on the microstructure and hardness of the Ti6Al4V alloy. Mater Sci Forum. 2015;828-829:194-9.

4. Zhang X, Chen Y, Hu J. Recent advances in the development of aerospace materials. Prog Aerosp Sci. 2018;97:22-34.

5. Karimzadeh F, Heidarbeijy M, Saatchi A. Effect of heat treatment on corrosion behavior of Ti-6Al-4V alloy weldments. J Mater Process Technol. 2008;206:388-94.

6. Ducato A, Fratini L, Cascia M, Mazzola G. An automated visual inspection system for the classification of the phases of Ti-6Al-4V titanium alloy. Computer Analysis of Images and Patterns. 2013;8048:362-9.

7. Ren L, Xiao W, Han W, Ma C, Zhou L. Influence of duplex ageing on secondary $\alpha$ precipitates and mechanical properties of the near $\beta$-Ti alloy Ti-55531. Mater Charact. 2018;144:1-8. 
8. Santosh R, Geetha M, Saxena VK, Nageswararao M. Studies on single and duplex aging of metastable beta titanium alloy $\mathrm{Ti}-15 \mathrm{~V}-3 \mathrm{Cr}-3 \mathrm{Al}-3 \mathrm{Sn}$. J Alloys Compd. 2014;605:222-9.

9. Lin YC, Tang Y, Zhang XY, Chen C, Yang H, Zhou KC. Effects of solution temperature and cooling rate on microstructure and micro-hardness of a hot compressed Ti-6Al-4V alloy. Vacuum. 2019;159:191-9.

10. Lin YC, Tang Y, Jiang YQ, Chen J, Wang D, He DG. Precipitation of secondary phase and phase transformation behavior of a solution-treated Ti-6Al-4V alloy during high-temperature aging. Adv Eng Mater. 2020;22:1901436.

11. ASTM International. Standard Practice for Preparation and Use of Direct Tension Stress-Corrosion Test Specimens. ASTM
G49, Annual book of ASTM Standards. West Conshohocken: ASTM International; 2005.

12. ASTM International. Standard practice for the preparation of stress corrosion test specimens for weldments, ASTM G58, Annual book of ASTM Standards. West Conshohocken: ASTM International; 2005.

13. ASTM International. Standard methods of tension testing of metallic materials, ASTM E8, Annual book of ASTM Standards. West Conshohocken: ASTM International; 2005.

14. Donachie MJ, editor. Titanium - a technical guide. West Conshohocken: ASM International; 1988.

15. Johnston RL, Johnson RE, Ecord GM, Castner WL. Stresscorrosion cracking of Ti-6A1-4V alloy in methanol. Washington: NASA; 1967. 